\title{
The Modern Examination of Confucian Filial Ethics
}

\section{Feilong Feng}

School of Humanities, Economics and Law, Northwestern Polytechnical University, Xi'an, China

Email: ffl1972@126.com

How to cite this paper: Feng, F. L. (2020). The Modern Examination of Confucian Filial Ethics. Open Journal of Social Sciences, 8, 286-294.

https://doi.org/10.4236/jss.2020.812023

Received: October 29, 2020

Accepted: December 21, 2020

Published: December 24, 2020

Copyright $\odot 2020$ by author(s) and Scientific Research Publishing Inc. This work is licensed under the Creative Commons Attribution International License (CC BY 4.0).

http://creativecommons.org/licenses/by/4.0/

\begin{abstract}
Filial ethics is an important part of the Confucian culture. As the corner-stone of the feudal ethics and morals, even with a strong color of feudalism, filial ethics is useful for the standardization of words and deeds in the modern world. Coming into the new era, we should take a dialectical and critical view of the Confucian filial ethics and inherit its positive elements. It will be of great significance in improving individuals' moral cultivation, strengthening the ethical ties of both the family and society, and spreading the Chinese traditional virtues.
\end{abstract}

\section{Keywords}

The Confucian Tradition, Filial Ethics, Critical Inheritance, Modern Review

\section{Introduction}

In the long history of the Chinese nation, "filial ethics" is the core of morality and ethics, the foundation of all trades, the precedence of all pieties, and a virtue mostly praised by the Chinese descendants. "Filial ethics" was assumed as one of the core ideas of the Confucian culture and the feudal society. It mainly includes the basic contents of raising relatives and respecting relatives, filial piety, admonition and filial piety, funeral and filial piety ( $\mathrm{Hu}, 2009)$. It refers to a kind of goodness and virtue of children to their parents, as well as a moral quality that junior should have for their elders (Xiao, 2006). It is not only an individual's natural feelings for his kinsmen, but also closely related to the destiny of the whole nation. It has great theoretical and practical significance for the development of the traditional Chinese spirits, for the standardization of human behaviors, and for the establishment of a harmonious society. 


\section{The Historical Origin of the Confucian Filial Ethics}

The ethics of filial piety is mainly embodied in the education of gratitude in western countries. The ancient Greeks regarded filial piety as one of the moral norms, but did not rise to the national level and system of values, they focused on the issue of filial piety. Japan, South Korea, Singapore, Malaysia and other countries, the Confucian ethics of filial piety as the maintenance of family relations, promote the basic concept of social harmony (Yu \& Zhang, 2007). In China, the concept of filial piety originated from the worship of ancestors in primitive society, which formed the behavior and norms of ancestor worship. With the development of the society, the behavior of "respecting the elderly" changed from the development of all the elders of the clan to the development of filial piety to parents (Chen, 2004). As a classic work of the Confucian ethics of filial piety, the Book of Filial Piety was listed in the Thirteenth Canon, which systematically elaborated the ethics of filial piety and became the moral norm and code of conduct for people from all walks of life (Liu, 2014).

The word "Filial piety" is a pictograph, which first appeared in the Shang Dynasty, symbolizing a child serving and holding the old man (Yang, 1980), but not enough to prove the establishment of the concept of filial piety. "Erya-Shixun" yun: "Good parents for filial piety", Xu Shen's shuo Wen Jie Zi explains "filial piety" as "good parents", that is, close to the old, close to illness, close to death, in other words, the children care for the old, care for the old, well-buried old. A large number of records emerged concerning "filial piety" till the Western Zhou period, and the idea of "filial piety" had been produced and was very popular at that time. The concept of "filial piety" is based on blood relationship and individual family economy, as well as the establishment of the relationships between rights and obligations among the family members. But the full meanings of "filial piety" and the patriarchal ethics based on "filial piety" were not established and perfected until the Western Zhou Dynasty (Lan, 2000). The people of the Zhou Dynasty interpret the meanings of "filial piety" from two aspects. The first is the worship of the ancestors, and the second is respect and provisions for parents. That is to say, the descendants must make a worship of their ancestors and take care of their parents, confirming the position of the eldest son and the authority of parents in the family. The father loves his sons; and brothers get along well with each other, thus, establishing the stability and harmony of the clan and family (Zhu, 2003), which all reflects the ethical nature that the clan members must be subordinate to the overall interests of the clan.

Confucius not only inherited the old tradition of "loyalty" and "filial piety" since The Zhou Dynasty, but also established the ethical thought system of "benevolence" based on "benevolence" and "courtesy", which showed that the father was kindhearted and the son was filial, and the brother was friendly. Confucius believed that "filial piety", reflected in the relationship between father and son, is that the son should "respect" and "not violate" the father, but the son can give correct opinions or Suggestions to the father (Pang \& Ge, 2014). Confucius' 
ethical thought of respecting his father and elder brother was further developed by Mencius and gradually became a common moral norm observed by all social strata. Mencius stressed the use of "filial piety" to educate the people, so that the people understand the ethics of filial piety, respect for elder brothers. On the relationship between emperor and minister, Mencius advocated "loyalty to the emperor"; In terms of family relations, Mencius advocated to be filial to parents at home and to care for friends when away from home. Mencius said, "There are three forms of unfilial piety, and the greatest is to have no descendants." We advocate "three years' mourning", but we should use what we can to bury our parents. We don't need to waste our money. It's just a good idea to show filial piety to the son of Man. Xunzi paid great attention to the study of rites. He believes that filial piety is not only about supporting parents, but more about respecting them. Xunzi filial piety is the feature of "filial piety" as a part of the ritual, everything is subject to the provisions of the ceremony, notice to shew piety as "the ritual", emphasize the people's moral behavior must obey the feudal legal system, but to the monarch, the lives of parents absolutely follow blindly, not totally convinced, because a monarch, the lives of parents has against the possibility of moral, Xun Zi the dialectical thought apparently has positive significance. Filial ethic culture as an important Confucian classics, the "filial piety" refers to a very high altitude, explicitly pointed out that "filial piety" is set by the specification, is the foundation of morality, the initial state of "filial piety" is respect for parents, middle state is monarch, served their own highest state is one of cultivating one's morality, and further puts forward to filial piety governance mode of governing, the heaven, tunnels and humanitarian together, so as to achieve "in" "rule" "rule the world", the purpose of obtaining the Han Dynasty and later by the feudal rulers (Tang, 2005). Since then, successive regimes have unified "filial piety" with "the way of Heaven" and further improved the Confucian ethical system of filial piety.

Thus it can be see, the Confucian thought of filial piety ethics has a long history, and especially it was developed and enriched by Confucius, Mencius and Xunzi. Filial piety not only helped the ruler govern the country, but also enhance the spiritual cultivation of the ruling class, made the society stable and cultivated a good social atmosphere. However, with the development of society, the Confucian filial piety ethics is gradually used by the feudal rulers, and becomes the spiritual shackles of people, which is mainly embodied in the Confucian ethics of filial piety.

\section{The Basic Content of Confucian Filial Piety Ethics}

Filial piety ethics plays an important role in the Confucian tradition, which is mainly expressed in the following aspects:

1) Treat parents well: As the Chinese nation's ethics, filial piety is derived from the nature of the blood relationship, whose basic connotation is to treat parents well. The filial piety is the fundamental of the humanity and the cornerstone of self-cultivation. In the view of Confucius, the essential difference be- 
tween man and animals is that people have virtue, and animals do not. So the essence of filial piety of the people is to have the sincere heart of showing filial obedience to our parents, rather than simply providing parents with food and drink perfunctorily. If the younger generation care for their parents materially but give no spiritual care, respect, caring and love, which has no any difference form livestock and is still lack of filial piety. Therefore, the Confucian filial piety ethics has always stressed that we must look after parents, be obedient to parents and respect parents, which is not only an ethical morality, but also a social behavior norm.

2) Miss and advise parents: Confucian filial piety ethics not only emphasizes the compliance with their parents, but also stresses that children cannot be absolutely unconditionally obedient to their parents. For parents' incorrect the words and deeds, we should put forward some suggestions and recommendations that makes our parents correct their mistakes, so that the children really show their filial piety. On the other hand, the Confucian school also stresses that the children should miss and care about their parents, not go away, and if they want to leave home, they should tell the parents of where they are going, so as not to make parents miss and worry overly (Luo, 2003), which reflects the deep affection of caring for parents.

3) Sacrifice, and remember their parents: Confucius paid special attention to the ritual burial of children and the ritual sacrifice. He said that he should express his respect for his ancestors with the feeling of sadness. He should do it with the amount of money instead of extravagance and waste, and always have the heart to sacrifice the deceased parents and ancestors. Ancestor worship in the Confucian tradition is an extension of the feeling of "filial piety" towards parents. By offering sacrifices to our ancestors, we feel the source of our own life power and extend our filial piety to all human relations, from which we understand the meaning and value of life itself.

4) Be loyal and obedient to the emperor: Confucianism believes that people should have a moral character and behavior criterion of loyalty, and that benevolent person must be conducive to others: if you want to do everything well, you need to cooperate with other people and help them to succeed, which actually describes the so-called loyalty. It is to interpret principles of loving others from the positive aspects, which is to achieve mutual respect and mutual tolerance between one another that is the basic stipulation of benevolence. Han Feizi was the first man who advocated supremacy of the royal power. The master of the Western Han Dynasty Confucian classics, Dong Zhongshu stressed that the monarch has absolute dominance over his subjects, the father has absolute dominance over his sons, and husband has absolute dominance over his wife, while the subjects have to obey the monarch absolutely, the sons have to obey his father absolutely, and the wife has to obey her husband absolutely. Thus, "loyalty" was changed from the original Confucian ethics category into a political and moral category, even the highest moral in traditional society.

The Confucian ethics of filial piety imply kindness, respect for parents, miss- 
ing and exhorting parents, offering sacrifices and remembering parents, and the virtue of being loyal to and attending to the emperor are interrelated and based on each other. Among them, kindness and respect for parents are the basic ethics and codes of conduct. Missing and exhorting parents reflect the true love for parents, which is the core of filial ethics; Offering sacrifices and remembering parents is the pursuit of filial ethics, which embodies the basic relationship of human relations and the essential meaning of life. The political connotation of filial piety is the virtue of loyalty to the monarch and serving the monarch, whose far-reaching significance lies in the sincere love for the motherland and the country. In summary, the traditional Confucian filial piety ethics has its rationality, such as respecting relatives, admonishing relatives, mourning for filial piety and offering sacrifices for filial piety, which are conducive to ascribe the development of social relations, self-cultivation, regulating the family, governing the country and controlling the whole world. At the same time, the Confucian filial piety ethics thought also has its disadvantages: it restricted the development of the human nature, and distorted the personality. Therefore, it is necessary for us to carry on the modern reflection and the examination of the traditional Confucian filial piety ethics.

\section{The Modern Value of Confucian Filial Piety Ethics}

There are obvious differences between Confucian filial piety ethics and the modern filial piety. Though along with the development of the times and social progress, the abuse of the Confucian filial piety ethics has become increasingly apparent and brings a certain negative impact on the society, family and individual. Meanwhile, different understandings of filial piety in different times caused some misunderstanding of Confucian filial piety ethics. Therefore, we must treat the Confucian filial piety ethics dialectically.

\subsection{The Historical Limitations of Confucian Filial Piety Ethics}

The historical limitation of the Confucian filial piety ethics is obvious, which is mainly embodied in the following aspects:

Firstly, the ruling class's great promotion of the "filial piety" made the "filial piety" ideology the basic moral force of the feudal autocratic rule and the shackles of the people. In the feudal society, the ruling class established with the absolute authority of the emperor as the foundation of the feudal control of their world. The emperor is the Son of Heaven and the authority of a country, who has the supreme power and orders the world. The father is an elder member of a family who has the power to give orders to the family members. Filial piety ethics thought praised highly absolute filial of the parents, which can be extended to be loyal to the monarch of their country and obeyed the orders of parents' "filial piety", which will develop as the "fealty" to the king, so the filial piety and loyalty are linked with each other (Shen \& Wang, 2005). In addition, the ruling class put forward the idea that filial piety is the premise of loyalty, loyalty is the inevitable 
result of filial piety. Therefore, the filial piety ethics of looking after parents and respecting elders objectively became the tool of maintaining the feudal rule. Therefore, we should abandon it.

Secondly, the feudal filial piety was to publicize the absolute obedience of the son to the father, and deprived the independent personality of their children. Listening to the teachings of the parents is to be perfectly logical and reasonable, which is a good tradition. But the feudal filial piety requests that children and grandchildren should be obedient to the will of parents, even when parents' education is incorrect and unreasonable, we should also absolutely obey, which is all clearly against the common sense. The absolute obedience reflected hierarchy approaches between seniors and juniors, parents and children, young and old in the feudal society, but ignored the individual consciousness. It can be seen that the absolute obedience to the parents of the feudal filial piety is not only conducive to family harmony and the formation of children's independent personality, but also affects the progress and development of the society. In this regard, we should give a firm denial and thorough criticism.

\subsection{The Modern Interpretation of Confucian Filial Piety Ethics}

In the contemporary society, it is very important to realize the transformation from the traditional filial piety to the modern filial piety. We should also draw on the positive factors of the traditional filial piety. It is necessary for us to give a modern interpretation of the Confucian filial piety ethics:

Firstly, the Confucian filial piety ethics thought pays attention to the equality between people and people. Traditional Confucian ethic of filial piety on one side reflects hierarchy inequality between person and person, on the other hand reflects their equal relationship in personality, namely the father's love for his children and children's filial piety are mutual. There exists a causal relationship between a loving father and a filial son. The interdependent relationship between father and son implies that the Confucian filial piety ethics also pays attention to the personality equality between the father and the son, monarch and subjects and siblings, which is good for the establishment of harmonious family and society.

Secondly, the thought of Confucian filial piety embodies the mutual benefit between the parents and the children. Traditional Confucian filial piety ethics holds that children must support parents, respect elders, give some kind advice and miss parents, which reflects that to some extent, there is no longer an absolutely unequal relationship between parents and children, namely, the parents are not necessarily authoritative dictators while the children are not necessarily obedient followers. But there exists mutual benefit obligations and responsibilities between them. Parents have the obligations of custody, security and the education of the children, simultaneously children have the obligations of loving, raising, advising and showing filial obedience to parents and elders. The two don't conflict each other, but benefit each other (Zhao, 2004). Now, the mutual 
benefit of the people in terms of obligations has been more and more embodied, which gets the recognition and protection of the law.

Thirdly, the Confucian filial piety ethics thought strengthens the emotional interaction between people. The Confucians put emphasis on what you don't want, do not impose on others. Solidarity, care and kindness can make people live in harmony and treat each other friendly. All these behaviors embody that the Confucian ethics of filial piety pays more attention to the interaction and communication between people and people, which has the great significance for the harmonious family atmosphere and harmonious society.

\subsection{Inheriting the Modern Value of Confucian Filial Piety Ethics}

Firstly, we should strive to improve the personal moral cultivation. Our country is a modern socialist country. The country is a big family of the individuals, which is made up of many individuals. If we want to build a modern and strong nation forever, it is essential for us to strengthen and improve personal moral cultivation. The Confucian ethics of filial piety emphasizes the promotion of the personal moral self-cultivation, regulating of people's words and deeds, and taking the individual's social responsibility and so on, which are virtues of formed in the historical development of the Chinese nation. In the new period, we absorbed dialectically and drew lessons from the reasonable factors of the Confucian filial piety ethics thought, which is not only the main content of the promotion of individual moral cultivation, but also the fundamental guarantee for strengthening the construction of socialist spiritual civilization, and more conducive to the development of socialist builders and successors.

Secondly, we should make efforts to strengthen family ethics education. All the good virtues of filial piety are the source of human feelings. Ideas about the family ethics as advocated by the Confucian filial piety ethics are conducive to regulating and maintaining family's order, correcting the family ethical behaviors. The spiritual essence of traditional Confucian ethics of filial piety is mainly reflected in children's showing filial piety to their parents and parents' care and love for the young. It requires us to strengthen family ethics education in the new historical period. First, we should cultivate children's love for their parents. In daily life, children and parents are required to carry out emotional communication. Parents should care about their children, and children should respect and honor their parents. Second, we should strengthen the education of the children's responsibilities for their parents. Children not only have to be thankful for their parents, but also to repay their parents in action. Finally, we should promote intimacy and equality between the children and the parents. We should actively advocate "fathers are kind and children are obedient", "A Jack make a good Jill", "the husband and the wife respect each other like guests" and so on (Li, 2001), which promotes the harmony of the family.

Thirdly, we should vigorously carry forward the patriotic tradition. The Chinese nation is a nationality with a long tradition of history. In the five thousand 
years of culture, loyalty and patriotism are considered the core of Chinese culture. Of course, patriotism is not the love and fidelity of the feudal dynasties, but loyal to the patriotic passion of lofty national integrity and enthusiasm. We must unify the patriotism with fundamental interests of the nation, the state and the people, demonstrate the unyielding national integrity and national character of the Chinese nation with patriotism as the core, eventually inspire people's ambition in the history and stimulate the cultural treasures of patriotic spirit (Huang, 2009).

\section{Conclusion}

In a word, as one of the core contents of excellent traditional Confucian culture, filial piety ethics plays an important role in standardizing and constraining people's behaviors and promoting family and social harmony. The Confucian ethics of filial piety are about treating parents well, respecting them, missing and exhorting them, offering sacrifices and remembering them, which fully demonstrate the traditional virtues of respecting and respecting the elderly of the Chinese nation. It also shows that only when people learn to respect their parents, will they love others, the collective, the society and the motherland. At the same time, Confucian filial ethics thought also has its limitations in terms of modernity. Although its discussion on the virtue of loyalty and vassal to the emperor contains love for the motherland, it also contains the thought of personality worship and the consciousness of "family" in the feudal society. Therefore, we should examine it dialectically, resolutely criticize and discard its dross, and inherit and carry forward its essence. In the new era, we should make an accurate judgment on Confucian filial piety and ethics, and carry forward its positive factors creatively, which will be conducive to further improving personal moral cultivation, strengthening family ethics and morality education, and then carrying forward the traditional education of patriotism, which will surely further promote the great rejuvenation of the Chinese nation.

\section{Conflicts of Interest}

The authors declare no conflicts of interest regarding the publication of this paper.

\section{References}

Chen, D. S. (2004). Confucian Filial Piety and Its Practical Significance. Studies of Confucianism, 4, 74-75.

Hu, P. S. (2009). Hu, P.S Chapter Filial Rule. Beijing: Zhonghua Book Company.

Huang, N. Y. (2009). Reflections on Carrying out Filial Piety Education the Contemporary in College Students. Journal of Shaoxing University, No. 5, 19-22..

Lan, L. (2000). Essence of the Doctrine of Confucius and Mencius. Beijing: Xinhua Publishing House.

Li, H. (2001). Establishing Modern Pension System and Carrying forward the Traditional 
Endowment Culture. Population Journal, No. 2, 48-50.

Liu, J. Y. (2014). On the Political Connotation in Xiaojing. Confucius Studies, 4, 19-22.

Luo, G. J. (2003). Filial Piety and Chinese Traditional Culture and Traditional Morality. Morality and Civilization, 3, 79-80.

Pang, B., \& Ge, X. Y. (2014). An Analysis of Filial Ethics and Its Meanings in the Analects of Confucius. Intelligence, No. 6, 263.

Shen, S. H., \& Wang, F. X. (2005). History of the Chinese Ethics (Vol. 1). Beijing: People's Press.

Tang, J. J. (2005). On the Family Ethics in Pre-Qin and Han Dynasty and Its Modern Value. Xi'an: Shaanxi Normal University.

Xiao, Q. Z. (2006). Ethics and Tradition. Beijing: People's Publishing House.

Yang, B. J. (1980). The Analects of Confucius. Beijing: Zhonghua Book Company.

Yu, Y. H., \& Zhang, X. H. (2007). Theory of the Modern Value of Filial Piety Culture. Journal of Ethics Research, 3, 69-72.

Zhao, J. H. (2004). The New Development of the Studies of Confucianism in the 21st Century. Beijing: Social Science Literature Press.

Zhu, Y. T. (2003). The History of Chinese Traditional Ethics. Shanghai: East China Normal University Press. 